\title{
Introduction: why apply industrial policy to the health industry?
}

\section{Marco R. Di Tommaso and Stuart O. Schweitzer*}

\section{INTRODUCTION}

An important goal of most industrialized countries is to promote its high-technology sectors, such as aerospace, pharmaceuticals, biotech, and telecommunication. These countries fear being left behind in the race for supremacy in each of these fields. An important issue facing any country desiring to compete is the appropriate role of government in these efforts. Many countries have a long tradition of promoting favoured industries in Europe and Asia, such as Italy, France, Germany, Japan and Korea. The USA has less of an explicit attitude toward this policy. Nonetheless, even the USA has engaged in strong government-supported industrial assistance programmes in areas including aerospace, aircraft, computer chips and flat display screens. Approaches are often less direct than those in Europe and Asia, but they are no less strong.

\section{WHY SHOULD HIGH-TECHNOLOGY INDUSTRIES BE PROMOTED?}

The issue of industrial promotion is one of the most debated in our recent history (Deane, 1989). However, it should be emphasized that this issue has taken on special significance in recent years because of the growth of hightechnology, knowledge-based industries, and new answers are sought to develop, foster or protect these new industries. ${ }^{1}$

Dominant economic theory has reached the conclusion that, with few exceptions, government intervention is likely to lead to less, rather than more, efficiency: in this context, according to mainstream Economics, there is no need for industrial promotion policy. Nonetheless, if one looks at the last two centuries of our industrial development history, industrial policy has always existed and it continues to exist in almost every country (Gerosky, 1989; Chang, 1994; Cowling, 1999). ${ }^{2}$ 
Different perspectives, or points of view, exist pertaining to the appropriateness of industrial policy, and it is difficult to develop an exhaustive taxonomy of rationales. However, in synthesis, we may argue that it has typically been justified on two grounds, as we show in Figure 1 .

The first is economic efficiency. This argument, rooted in the dominant economic theory, is that markets will sometimes fail, for various reasons, and intervention may be needed to restore efficient allocation of resources (Musgrave and Musgrave, 1984; Stiglitz, 1988). Basic textbooks of economic theory justify government intervention primarily to address inefficiencies caused by market failures. These market failures result from the existence of public goods, externalities, declining long-run average costs and insufficient competition. In this context, industrial policy may be called upon to correct these market failures. In the case of high-tech sectors, these interventions are often related to research, innovation, infrastructure, local development, antitrust policy and regulation. For example, market forces in some circumstances may not guarantee enough innovative capacity in an industry. In other common cases crucial public goods (such as knowledge, information and know-how) may be underprovided owing to non-rivalness, nonexcludability and the free-rider problem. In these cases policy intervention may help the productive system to follow more desirable and efficient paths.

The second typical rationale in favour of government intervention refers to criteria that go beyond efficiency (see Figure 0.1). Experiences around the world suggest that there are additional justifications based on strategic objectives (such as employment and national competitiveness) and based on what we may define as meta-economic objectives (such as distribution of wealth and economic opportunity) (Chang, 1994; Amsden, 1989).

In this context, there are lessons to be learned from the experiences and practices of successful economies like France, Italy, Japan, Korea and China. In many cases in these countries, industry has been promoted for reasons that go beyond efficiency criteria and the correction of market failures. In many of these cases industry has been promoted for strategic reasons because government has wanted to protect infant industries, maintain declining sectors, or support 'national champions'. In the past, strategic sectors have included motor cars and steel. Today, the sectors that are considered strategic in all highly industrialized countries (and some emerging countries) include new industries such as electronics, telecommunications and biotechnology. In these cases, justifications for governmental intervention go beyond issues of market failure discussed above. However, again, if we analyse the histories of industrial development it is clear that in many countries - developed, developing and in transition - industries have also been favoured or promoted for reasons that we may define as either paternalistic or 'meta-economic', meaning beyond traditional 


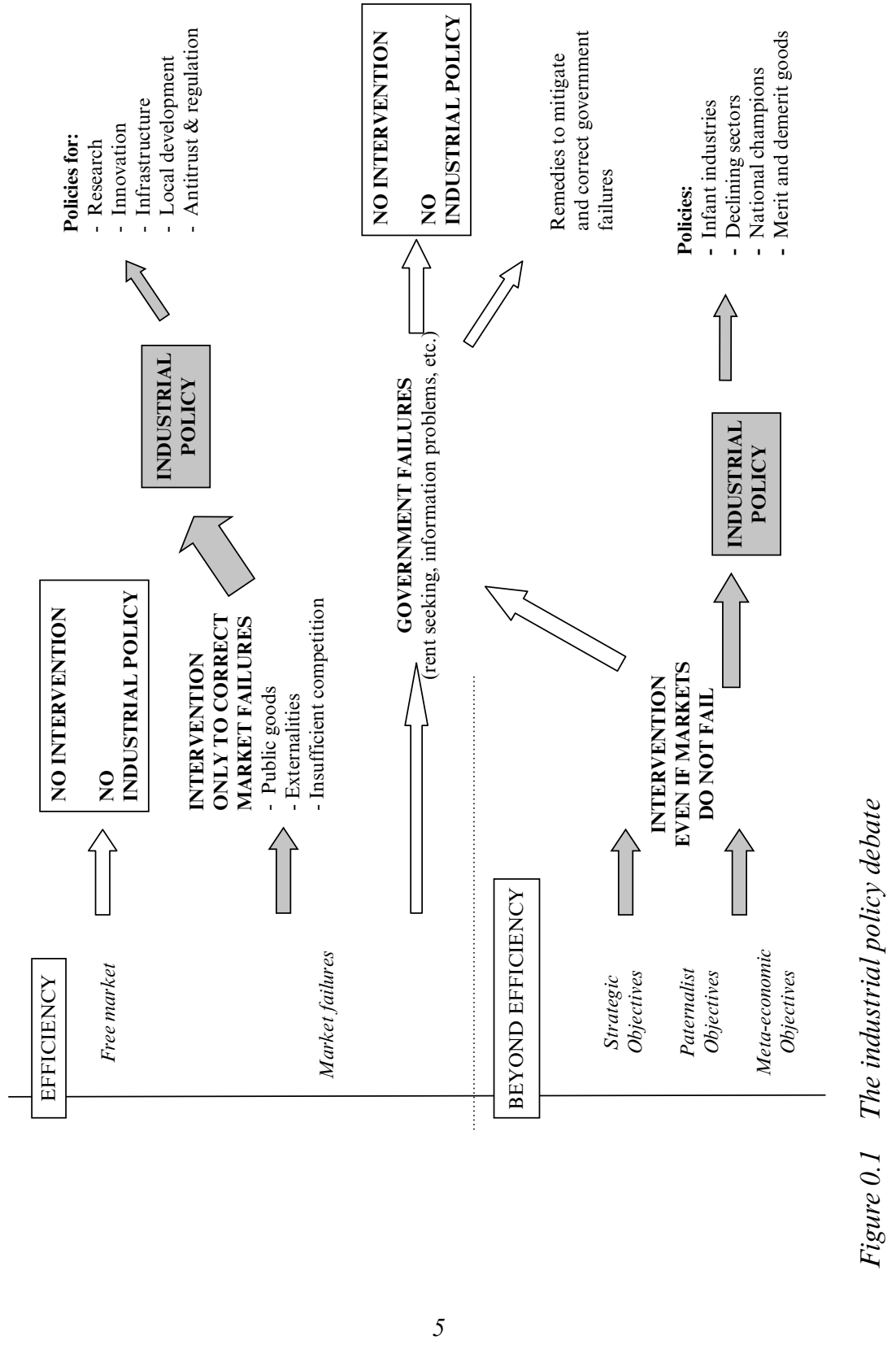


economics rationales. Here industry is seen as an instrument to achieve wider goals, including access to knowledge and health, improved distribution of wealth, and social or environmental sustainability. Government promotion of hi-tech sectors such as telecommunications and biogenetics are frequently justified in these ways.

Of course, today it is also clear that government interventions may be unsuccessful, and then in many cases one must choose between the ills of a failed market or the ills of a failed intervention policy (Chang, 1994; Stiglitz, 1987; Simon, 1983; Buchanan et al., 1980; Kueger, 1990).

Government policy failures may cost more than the benefit the intervention is supposed to offer. In this case, it may be preferable to accept market failure rather than the consequences of failed government remedies. For example, an innovation and research policy designed to solve problems of market failure may be ineffective for several reasons, including rent seeking, information problems or distortions caused by particular interest groups. In these cases, we may be ready to deny the need for public intervention promoting innovation and research in high-tech industries.

However, in a symmetrical way, it also has to be argued that both market failures and government intervention failures may be correctable, at least in principle. In the past, people have focused attention on corrections to market failures, but remedies to failures of government policy may also be found. Therefore, before accepting failures in markets because government failures are more serious, one ought to analyse the causes of government failures and search for remedies for them.

For example, a government intervention policy designed to address freerider problems in basic research may fail. But, before one accepts the original market failure, one must consider actions that would improve the performance of the government policy intervention.

\section{THE HEALTH INDUSTRY AS A SPECIAL CASE OF THE KNOWLEDGE-BASED INDUSTRIAL SECTOR}

It is customary among health policy analysts to talk of the necessity of reducing health expenditures (Department of Health, 1998). The cry to cut health costs becomes louder with each report documenting ever-higher health expenditures. The US Economic Report of the President (2002) notes, for example, 'There is . . growing evidence that substantial opportunities remain both to reduce costs and to achieve greater improvements through more effective use of medical services - that is, to improve the value, or output per dollar spent, of our health care system'. The rationale for this 
urge to reduce health expenditures is the assumption that the objective of a nation's health system is to produce an acceptable level of health at minimum cost. We call this objective 'the Health Model'. The Health Model portrays health services as an input in a production function that has health as the only output. The responsibility of the health system is to produce an acceptable level of health as efficiently as possible (see, for example, Cochrane, 1972). The task is difficult because it is not easy to determine what the 'acceptable' level of health is for a particular population. People's preferences differ widely in terms of health and other determinants of consumer satisfaction, and some contend that it is in fact impossible to aggregate personal utility functions to determine what society prefers. By stating that the only objective of the health system is to produce health, it is reasonable to demand efficiency in the system, such that the acceptable level of health be produced with the minimum level of expenditures.

Another view of health systems, however, considers other objectives than health status. This other view suggests that the health system also produces benefits for an economy in terms of economic externalities that result from investment in research and development, and it can produce services that will be sought by the world economy and hence produce valuable export earnings. We call this view 'the Health Industry Model'. The Health Industry Model views the health industry's outputs in the framework of a multi-product production function, in which health and other outputs are produced by health providers and health manufacturers. The Health Industry Model suggests that the health sector comprises a large number of interconnected industries that produce both health services and manufactured goods, including pharmaceuticals and diagnostic equipment. The health industry is not the only industry that produces broader societal benefits in addition to its stated mission. Educational systems, for example, produce broader benefits than knowledge, spilling over to improve labour productivity, political awareness and cultural enrichment. But the health industry is particularly interesting in being able to produce broader technological development, as well as health, because of its high-tech nature. The Health Industry Model is described in detail in the first chapter of this volume, by Di Tommaso and Schweitzer. The health industry contains three clusters of industries: health care providers, health care financiers, and health manufacturers. The structure of the health industry is shown in Figure 0.2 .

Health care providers consist of both institutional and communitybased organizations. Institutional organizations are hospitals, nursing homes, mental hospitals and so forth, while community-based organizations include ambulatory care clinics, community-based medical practices, 


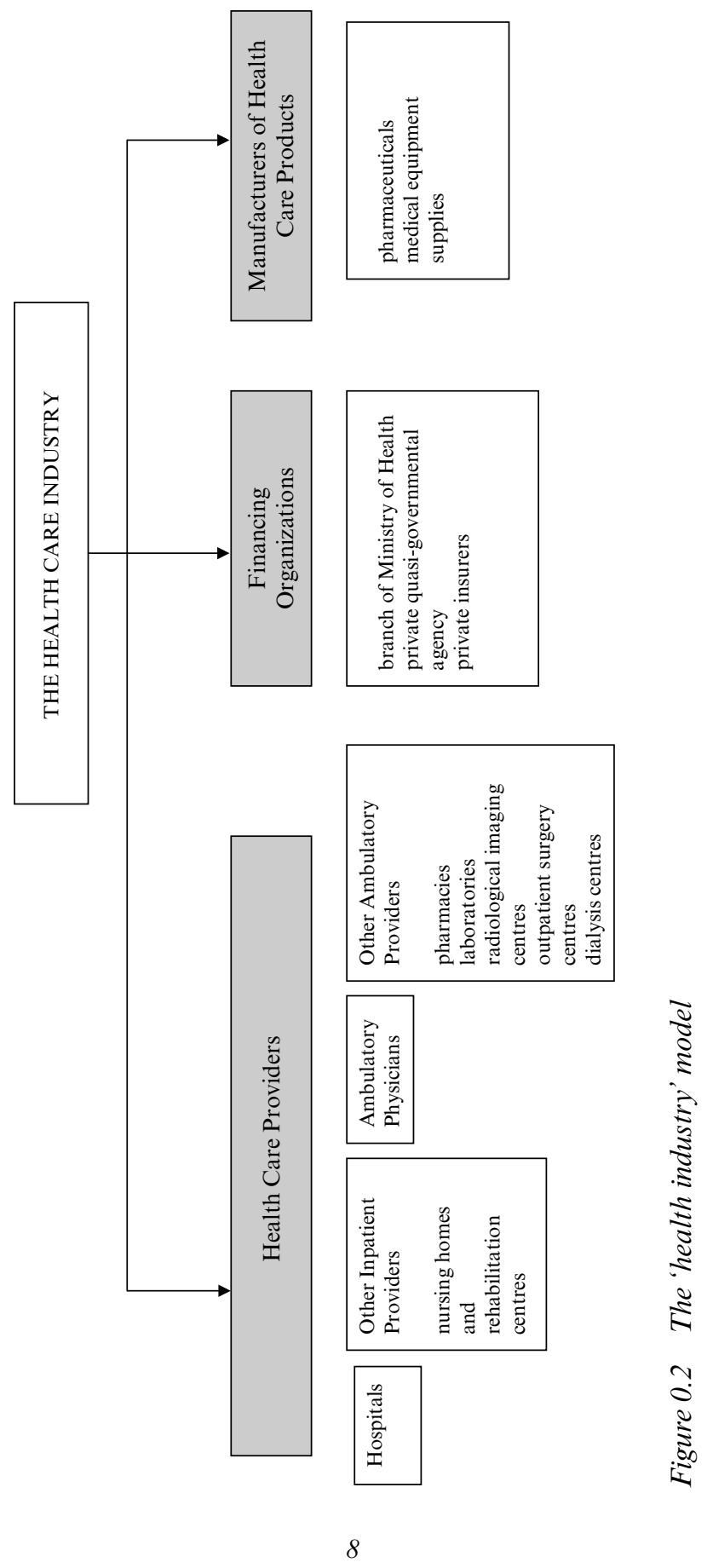

Marco R. Di Tommaso and Stuart 0. Schweitzer - 9781845424565 Downloaded from PubFactory at 04/26/2023 01:38:19PM 
home-based care programmes such as Visiting Nursing and home-based hospice services. The ownership of institutions varies from country to country. In some countries, such those in Europe, most hospitals are government-owned, while, in the USA, most hospitals are private, though some are owned by state or local governments. In most countries community-based physicians are independent entrepreneurs, though in some countries they are civil servants, employed by government. In recent years there has been a substantial shift in the locus of care from institutional providers, such as hospitals, to home-based care programmes.

Health care financiers are similarly either public or private. Most countries have health care financial systems that are either public or quasipublic. The USA is remarkable for funding over half of national health expenditures through private health insurance firms. Public expenditures in the USA, however, are very large, consisting primarily of the Medicare programme for the elderly and the 50 state Medicaid programmes for the indigent (Health United States: 2003). In other countries, though public financing of health care predominates, private insurance coverage is expanding and the share of privately financed health care is increasing. Therefore, though the relative proportions of public and private financing differ between the USA, European countries and Japan, most financing programmes in industrialized countries are, in fact, mixed, with public and private funding coexisting.

The third group of industries in health care comprises health product manufacturers. These firms are well known for manufacturing pharmaceuticals and diagnostic and therapeutic medical equipment, such as radiology and dialysis machines, and laboratory testing equipment.

Two important observations about the health industry follow from this discussion. The first is that the outputs of the health industry are varied and complex. In contrast to most industries, the outputs are both products and services. This is a major reason why cost containment is so difficult in health, because the production process in that part of the industry that is producing products is relatively transparent, while the production process for services is less so. Inputs are difficult to quantify and so are outputs, because quality, as well as quantity, are important dimensions of output.

The second observation is that virtually all of the health industry's components are interconnected, forming a complex system of providers, insurers and manufacturers. This is why efforts to reduce overall health expenditures by reducing expenditures in one industry (for example, hospitals) so often fail. Decreases in one industry's expenditures are likely to lead to increases in expenditures of other industries (for example, pharmaceuticals and ambulatory care). And when administered prices in one 
industry are reduced (for example, by lowering physician reimbursement rates), increased utilization of substituting services, including hospital care, emergency room visits and pharmaceuticals, are likely to result. It is often observed that the pharmaceutical industry, for example, both substitutes for other health services, and complements them (Comanor and Schweitzer, 1994).

The objectives of the health industry are difficult to ascertain. While most health systems are regulated according to the traditional view that a health system's objectives are to produce an acceptable level of health for a population at minimum cost, the health system is more complex than this simple mission would suggest. In addition to maintaining a population's health status at some acceptable level, the health system is a major generator of scientific knowledge through its research and development functions. Increases in health status produce not only social welfare, but also increased productive capacity of a nation's workforce. This effect of health status on economic development in developing countries has been noted by the World Health Organization (World Health Organization, 2002). The effect of health on both the educational system and the labour force applies as well to industrialized countries, but the benefits of a strong health industry are not limited to direct health effects. Scientific knowledge and productive capacity produce benefits throughout the economy. Therefore these benefits are described as 'public goods' and, if left to individual markets to produce, they will be underproduced. No firm has a sufficient incentive to invest in knowledge or worker health, because the benefits extend far beyond the single firm. The health industry is also capable of producing other benefits, such as 'national champions', industries in which a nation can take pride, especially when this industry represents new technological breakthroughs. A last consideration is that high-technology industries typically start out small and need 'nurturing'. With sufficient protection and public investment, there is the hope that industries will grow to be selfsustaining. Examples include biotechnology and the new field of nanotechnology (the production of ultra-small structures that can be used to construct very strong materials or devices). The existence of a wide range of health industry outcomes suggests that government has an important role in funding those functions of the health industry that produce these broad benefits.

Understanding the multi-objective role of the health industry explains, in part, why policy decisions affecting the size of the health industry are often so contentious. There is a conflict between those who see the health industry as responsible only for producing an acceptable level of health (at minimum cost) and those who see broader benefits of a dynamic, scientifically sophisticated health industry. The perception of broader 
benefits from the health industry justifies increased government investment to address market failure concerns and other objectives of a country's health industry.

Government policies towards the health industry can be described in terms of the degree of central authority inherent in a policy. National policy can be characterized as a 'macro' activity: the set of policies designed to affect an entire economy. Policies can also be directed at the level of the firm itself. The focus of these policies can be called 'micro'. Then there is a level of policy analysis that is neither macro nor micro, but rather based upon agglomerations of firms and institutions, usually within a single industry, though not necessarily so. These agglomerations are referred to as 'industrial clusters'. Considerable interest is expressed these days in developing policies that will encourage the establishment and growth of these industrial clusters, especially those that concentrate in high-technology industries such as biotechnology.

The book follows this three-part framework in focusing on industrial policy in the health industry. The first chapter, by Di Tommaso and Schweitzer, describes a new view of a nation's health system and justifies an increased role for government in promoting the health industry. The traditional view of a health system, called 'the Health Model', is that its objective is to produce an acceptable level of health for its population at minimal cost. The new view, called 'the Health Industry Model', suggests additional policy objectives, most prominent of which is the production of knowledge and innovation that will spillover into other industries. The implication of this model is that many health system activities are in the realm of public goods and must be financed by government rather than by individual providers of manufacturing firms.

\section{POLICIES TO ENCOURAGE DEVELOPMENT AND ADOPTION OF NEW TECHNOLOGY}

\section{Three Perspectives: Macro, Micro and Intermediate-Level}

In the remaining chapters of this volume we look at industrial policy in the health industry from three viewpoints. The first, the economy-wide macro view, looks at the effect of government policies in encouraging innovation and high-tech industrial development. The second view, the micro view, discusses both production of innovation and adoption of technological change by individual health industry actors: firms, universities, hospitals, and so on. Finally, we consider the intermediate level, which is neither economy-wide nor specific to a single actor: the industrial cluster, defined 
as a geographic agglomeration of firms and institutions operating within a single industry or a group of complementary sectors.

\section{The 'Macro View'}

How can governments encourage innovation, diffusion of knowledge and adoption of new technologies with broad policies? Three chapters in this volume deal with these macro-oriented policies.

In Chapter 2, Branston, Rubini, Sugden and Wilson are concerned that broad strategic health policy decisions may be made, not in the interest of a nation's constituency, but rather by elite groups within each firm in the industry. One implication of this may be that decisions concerning investment in innovation in the health industry may reflect the wishes of administrators and managers rather than the needs of the population. Two levels of failure occur in this scenario. The first is that single health providers may not adopt innovation or improve quality to the desired degree because provider objectives replace public objectives. The second is that the industry, without coordination, will produce less innovative and lower-quality health care than would be desirable to the broader constituency.

Chapter 3, by Vicarelli, poses three alternative strategies by which governments have attempted to contain health care expenditures. The first is a top-down approach of curtailing demand by restricting supply. The second approach introduces competition between providers in an attempt to increase provider efficiency. The third approach, initially implemented in Scandinavia, introduces cooperation and collaboration, rather than competition. In this approach providers take a more active role in defining regulation. In describing these three cost-containment strategies, the author provides a framework to assess which approach is best able to promote innovation and improve quality of care.

In Chapter 4, Comanor, Schweitzer and Carter look at another governmental policy area (price setting) as a determinant of research and development and innovation. The setting of this empirical study is the US pharmaceutical industry. In looking at pharmaceutical reimbursement, the study explores the relationship between market factors, product characteristics and prices for pharmaceuticals. The finding is that product characteristics - efficacy, safety and convenience - are important determinants of market prices of drugs. The implication of this finding for explaining variation across countries in investment in $\mathrm{R} \& \mathrm{D}$ is great, because the evidence is that consumers have strong preferences for drugs that excel along each of the three dimensions. Attempts to restrict prices for products that improve efficacy, safety or convenience will restrain investment in innovation and consumer welfare will be reduced. 


\section{The 'Micro View'}

Macro policies to facilitate innovation and technological change are important, but are insufficient in themselves. Individual institutions must be willing to innovate and accept change. We present three chapters that look at the way particular actors in the health industry were able to adapt their structures to react to innovation and change. With few exceptions, development of new technology depends both on the system's capacity to produce innovation and on its ability to adopt, or absorb, new technology. A system characterized by actors that are unable to accept technological change will discourage innovation in the first place.

Vagnoni, Guthrie and Steane (Chapter 5) study the pivotal role of universities in developing new technology. The authors are particularly interested in university relationships with industry in sponsoring research. While acknowledging the vital role of the industrial sector in collaborating with universities, they point out that underlying core funding by government for basic research is essential for production of innovation.

The chapter by Bianchi and Labory deals with the concept of intangible assets in the pharmaceutical industry. The authors consider the role of spillovers in high technology industries, generally, consistent with the Health Industry Model. They suggest that it is the intangible assets, whose share of industrial asset value has increased dramatically in recent decades, that are largely responsible for the spillovers that occur between high-tech industries. They discuss the nature of intangible assets and how this particular type of asset affects a firm's ability to innovate and increase productivity and value.

In Chapter 7, Llewellyn and Northcott focus on government policy directed towards improving efficiency in hospitals. The authors analyse a UK initiative that publishes hospital cost data so that individual hospitals can see where they excel and where they are deficient in comparison to others. They argue that facilitating these comparisons could, in theory, improve provider efficiency by encouraging the implementation or adoption of efficiency-increasing innovation. On the other hand, interpreting and making use of these comparative cost data is more complex than might be expected and the UK experience shows that this attempt to increase hospital efficiency was less successful than was hoped.

\section{The 'Intermediate View'}

In-between macro policies and firms themselves, there is another emerging focus of industrial policy that is neither at the level of the overall economy nor at the level of individual firms. This is the agglomeration of 
firms and institutions within a geographic area, usually within a single industry, into high-technology industrial clusters. In many cases throughout the world, these clusters are the direct result of government policies. Other clusters, however, are the natural result of market forces, without government intervention.

It is often noted that industrial clusters have existed for centuries (Becattini, 1990). Furthermore recent literature in the field of industrial organization has noted the importance of these clusters in increasing industry efficiency and competitiveness. Most of this literature, however, refers to the industrial sector and not to high-technology industries. Some have suggested that the nature of high-technology industries (for example, the lack of need for physical proximity to inputs or markets) makes clustering in this sector obsolete (distance is obsolete). The evidence, however, is strongly to the contrary, and we and our colleagues point out that these clusters are as central to the development of 'new', high-technology industries as they were to manufacturing industries.

In the final part of this volume we present five chapters describing hightechnology industrial clusters in several countries. These chapters explain how it is that clusters arise, and what industrial policies appear to facilitate their appearance in different countries.

Chapter 8, by Di Tommaso, Paci and Schweitzer deals with clusters of firms characterized by intangible assets. An important example of this is the biotechnology industry. While one might expect that modern information technology would make spatial agglomeration of these firms unnecessary, the authors describe the particular rationale for these firms to cluster.

In Chapter 9, Schweitzer, Connell and Schoenberg develop further the ideas of the previous chapter. They present empirical evidence on factors that are associated with the existence of biotechnology clusters in the USA. The implications of this analysis are that universities are instrumental in being 'seed-beds' of biotech firm development, and that policies that stimulate basic research in universities are likely to lead to development of high-tech industrial clusters.

Chapter 10, by Hirsch, attempts in an innovative way to calculate the economic spillover effects of a university-sponsored industrial cluster on its region. A three-stage model is proposed and tested with reference to a large biotechnology cluster in California. The first stage of benefits is the direct university expenditure on goods and services in the cluster. The second, indirect, stage is the effect of these expenditures on the purchase of goods and services by those firms. The third stage consists of expenditures by employees of these firms. These three stages of benefits are a lower estimate of total benefits because additional indirect effects exist, but are even more difficult to measure. One of these is the effect of externalities and synergies 
by which growth of one industry produces benefits for other industries, either in the same region or further away.

Bellandi and Tessieri present a chapter dealing with relationships between Italian high-tech firms operating within a cluster and foreign multinational firms. The authors demonstrate that multinational firms will often seek existing industrial clusters in which to locate their firms or invest capital in order to exploit advantages and economies that they would otherwise be unable to achieve. These foreign-based firms then develop strategic linkages and alliances with the Italian firms already in the cluster.

Finally, Chapter 12, by Katz-Bénichou and Viens describes the development of two high-tech clusters in France. The authors point to an entirely different model of high-tech cluster development, suggesting that countries may have different ways of promoting industrial development.

\section{NOTES}

* We wish to thank Patrizio Bianchi (University of Ferrara and L'institute), Roger Sugden (University of Birmingham and L'institute) and William Comanor (UCLA) for their stimulating comments to a preliminary draft of this introduction.

1. Interventions can be direct or indirect. The Economic Report of the President (2002), for example, refers more to 'incentives' than to direct intervention in stating, 'It is important to establish incentives that will ensure continued growth in innovation and the new technologies that will define the 21 st century. We must not only invest in basic research, but also ensure that intellectual property of innovators is secure at home and abroad' (p. 62).

2. As Gerosky pointed out: 'any random collection of six economists is sure to produce at least a dozen different opinions on the subject, not least because many economists have trouble in reconciling their gut reaction that industrial policy should not exist with the obvious fact that it does' (Gerosky, 1989, p. 20).

\section{REFERENCES}

Amsden, A. (1989), Asia's Next Giant: South Korea and Late Industrialization, Oxford: Oxford University Press.

Amsden, A. (1994), 'Why isn't the whole world experimenting with the East Asian model to develop? Review of the East Asian miracle', World Development, 22(4).

Becattini, G. (1990), 'The Marshallian industrial district as a socio-economic notion', in F. Pyke, G. Becattini and W. Sengenberger (eds), Industrial Districts and Interfirm Cooperation in Italy, Geneva: International Institute for Labour Studies.

Buchanan, J., Tollison R. and Tullock, G. (eds) (1980), Towards a Theory of Rent Seeking Society, College Station, Texas: Texas A\&M University Press.

Chang, H.J. (1994), The Political Economy of Industrial Policy, London: Macmillan.

Cochrane, A.L. (1972), Effectiveness and Efficiency: Random Reflections on Health Services, Oxford: The Nuffield Provincial Hospitals Trust. 
Comanor, W.S. and Schweitzer, S.O. (1994), 'Pharmaceuticals', in Walter Adams and James Brock (eds), The Structure of American Industry, 9th edn, New York: Prentice-Hall.

Cowling, K. (ed.) (1999), Industrial Policy in Europe, London and New York: Routledge.

Deane, P. (1989), The State and Economic System, Oxford: Oxford University Press.

Department of Health (1998), The New NHS - Modern and Dependable: A National Framework for Assessing Performance, Leeds: National Health Service Executive.

Economic Report of the President (2002), Washington, DC: United States Government Printing Office.

Gerosky, P. (1989), 'European industrial policy and industrial policy in Europe', in Oxford Review of Economic Policy, 5(2).

Kueger, A. (1990), 'Government failure in economic development', Journal of Economic Perspectives, 4(3).

Musgrave, R. and Musgrave, P. (1984), Public Finance in Theory and Practice, New York: McGraw-Hill.

Simon, H. (1983), Reason in Human Affairs, Oxford: Basil Blackwell.

Stiglitz, J. (1987), 'The principal agent problem', The Palgrave Dictionary of Economics, vol. 3, London.

Stiglitz, J. (1988), Economics of the Public Sector, New York: W. Norton.

US Department of Health and Human Services (2003), Health United States, 2003, Washington, DC: US Government Printing Office.

World Health Organization (2002), Macroeconomics and Health: Investing in Health for Economic Development, Geneva: World Health Organization. 